\title{
Transition Core Properties During Conversion of the NBSR from HEU to LEU Fuel
}

\author{
A.L. Hanson and D.J. Diamond
}

November 2013

Nuclear Science \& Technology

Brookhaven National Laboratory

\author{
U.S. Department of Energy \\ National Nuclear Security Administration
}

Notice: This manuscript has been authored by employees of Brookhaven Science Associates, LLC under Contract No. DE-AC02-98CH10886 with the U.S. Department of Energy. The publisher by accepting the manuscript for publication acknowledges that the United States Government retains a non-exclusive, paid-up, irrevocable, world-wide license to publish or reproduce the published form of this manuscript, or allow others to do so, for United States Government purposes. 


\section{DISCLAIMER}

This report was prepared as an account of work sponsored by an agency of the United States Government. Neither the United States Government nor any agency thereof, nor any of their employees, nor any of their contractors, subcontractors, or their employees, makes any warranty, express or implied, or assumes any legal liability or responsibility for the accuracy, completeness, or any third party's use or the results of such use of any information, apparatus, product, or process disclosed, or represents that its use would not infringe privately owned rights. Reference herein to any specific commercial product, process, or service by trade name, trademark, manufacturer, or otherwise, does not necessarily constitute or imply its endorsement, recommendation, or favoring by the United States Government or any agency thereof or its contractors or subcontractors. The views and opinions of authors expressed herein do not necessarily state or reflect those of the United States Government or any agency thereof. 
BNL-102419-2013-IR

\section{Transition Core Properties during Conversion of the NBSR from HEU to LEU Fuel}

Manuscript Completed:

November 13, 2013

Prepared by:

A.L. Hanson and D.J. Diamond

Nuclear Science \& Technology Department

Brookhaven National Laboratory

Upton, NY 11973

Prepared for:

National Nuclear Security Administration

National Institute of Standards and Technology 



\section{ABSTRACT}

An equilibrium core consisting of low enriched uranium (LEU) fuel has been designed for a future conversion of the NBSR, which currently uses high enriched uranium (HEU) fuel. In the present study consideration is given to the transition period when the core may be partially loaded with both types of fuel. The transition is challenging due to reactivity constraints and the need to maintain an uninterrupted science program, the mission of the NBSR. The transition cannot occur with a one-time change of all HEU fuel elements since the excess reactivity would be larger than allowed by current technical specifications. For this report a gradual transition was studied wherein four fresh LEU fuel elements were placed in the core every fuel cycle following the same fuel management scheme currently in use. The properties of interest are the cycle length, shim arm reactivity parameters, kinetics parameters, power factors, reactivity coefficients, figures-of-merit for neutron beam performance, and actinide inventories at discharge. The study also looks at what happens after the transition cores are completed, and at the potential for a preliminary step involving the partial loading of LEU fuel (the so-called lead acceptance element approach) before the actual transition. 


\section{TABLE OF CONTENTS}

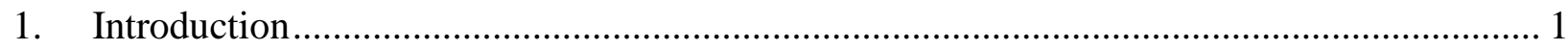

2. TRANSITION CORE PROPERTIES …..................................................................... 3

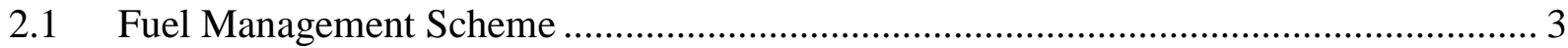

2.2 Reactor Model and Inventory Calculations............................................................... 4

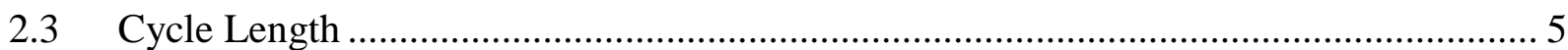

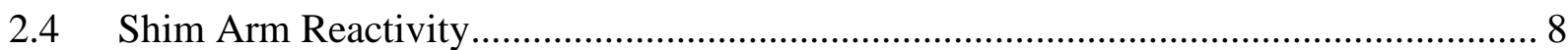

2.5 Prompt Neutron Lifetime and Delayed Neutron Fraction........................................... 9

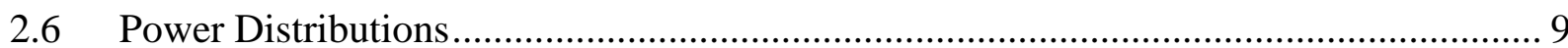

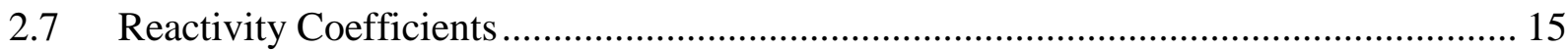

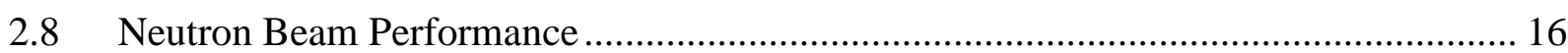

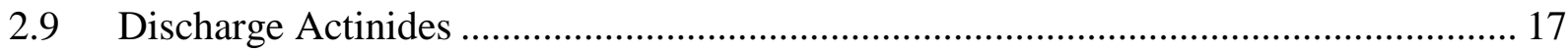

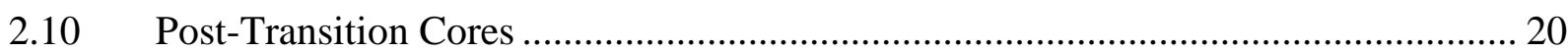

2.11 Alternative Starting Point for the Transition ...................................................... 20

3. SUMMARY AND CONCLUSIONS ....................................................................... 22

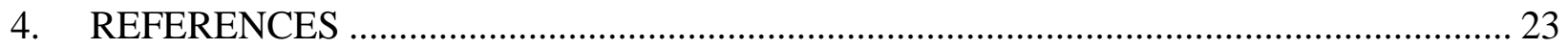




\section{LIST OF FIGURES}

Figure 2-1 Fuel Management Scheme ............................................................................. 3

Figure 2-2 Flow Chart for Generating Inventories in a Mixed Core with MCNPX.................... 6

Figure 2-3 $k_{\text {eff }}$ at EOC for Different TC1 Cycle Lengths and the HEU Core .............................. 7

Figure 2-4 Shim Arm Angle at SU for Criticality for each Transition Core ............................... 7

Figure 2-5 Radial Power Distribution for HEU Fuel at SU.................................................. 12

Figure 2-6 Radial Power Distribution for LEU Fuel at SU ................................................. 12

Figure 2-7 Radial Power Distribution for HEU Fuel at EOC .................................................. 13

Figure 2-8 Radial Power Distribution for LEU Fuel at EOC ................................................ 13

Figure 2-9 Power Generated in the Inner Six Fuel Elements at SU and EOC........................... 14

Figure 2-10 Power Generated in the Outer 24 Fuel Elements at SU And EOC ......................... 14

Figure 2-11 Multiplication Factor After Transition Cores ....................................................... 20

Figure 2-12 Flow Chart for Lead Acceptance Elements ..................................................... 21

\section{LIST OF TABLES}

Table 2-1 Number of Different FEs in Transition Cores ...................................................... 4

Table 2-2 Shutdown Reactivity, Shutdown Margin, and Excess Reactivity .............................. 8

Table 2-3 Total Shim Arm Worth....................................................................................... 8

Table 2-4 Prompt Neutron Lifetime and Delayed Neutron Fraction......................................... 9

Table 2-5 Hottest Spots, Stripes and Half Fuel Elements at SU............................................ 10

Table 2-6 Hottest Spots, Stripes and Half Fuel Elements at EOC............................................. 10

Table 2-7 Moderator Temperature Coefficient (MTC) .......................................................... 15

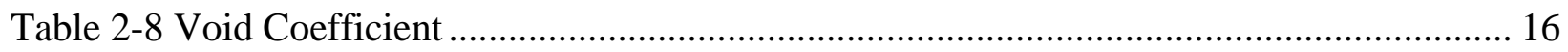

Table 2-9 Actinide Masses for Discharged 7-Cycle Fuel Elements .......................................... 18

Table 2-10 Actinide Masses for Discharged 8-Cycle Fuel Elements ....................................... 19 


\section{ACKNOWLEDGMENTS}

The authors benefitted greatly from the close support of the staff at the NIST Center for Neutron Research, which operates the NBSR. We thank Sean O’Kelly, Michael Rowe, and Robert Williams for their close collaboration. The authors appreciate the financial support of the National Nuclear Security Administration and the project management of John Stevens at Argonne National Laboratory. Thanks also to Lynda Fitz who ably performed all the administrative work for this report. 


\section{INTRODUCTION}

The NBSR is a 20 MWt research reactor moderated and cooled by heavy water $\left(\mathrm{D}_{2} \mathrm{O}\right)$ and using high-enriched uranium (HEU) fuel. The reactor is designed to provide thermal and cold neutron beams for research. The fuel elements have a unique design with a seven inch gap between the upper and lower halves. This gap is where the thermal neutron flux peaks so that beam tubes at that level have the advantage of the high thermal neutron flux while at the same time, since they do not point directly at fuel, have minimum "contamination" from high energy neutrons and gamma rays.

The conversion of the NBSR from HEU to low-enriched uranium (LEU) fuel is currently being planned. An LEU fuel element has been designed [(Hanson, 2011) and (Brown, 2013b)] that allows an equilibrium core to operate at full power for the 38.5-day fuel cycle that is currently considered optimum. The LEU elements replace the HEU dispersion fuel meat with a monolithic U10Mo foil where the uranium is enriched to only $19.75 \%$. The foil is not as thick as the dispersion fuel meat so the $\mathrm{Al}$ alloy clad in the $\mathrm{LEU}$ case is thicker. There is also a $\mathrm{Zr}$ interlayer between the foil and the clad in the LEU design. No other changes are made to the fuel element or the core.

The penalty in converting to LEU fuel is that the thermal and cold neutron flux available to experimenters is reduced. Based on the success of the HEU fuel cycle, the LEU fuel management scheme is identical, with four fresh elements introduced at the beginning of every cycle and two elements having gone through seven cycles and two having gone through eight cycles removed at the end of each cycle. The placement of fresh fuel on the core periphery helps optimize leakage. Keeping this same fuel management scheme minimizes changes to fuel loading/removing procedures. This LEU core has been shown to have neutronic and thermalhydraulic properties that allow it to operate safely [(Baek, 2013) and (Diamond, 2012)].

The question that the present study addresses is how to transition from the current equilibrium HEU fueled core to the equilibrium LEU core. Several alternatives have been considered and rejected. The conversion cannot be performed with a one-time replacement with fresh LEU fuel elements because the resulting excess reactivity would exceed the limit set in NBSR Technical Specification 3.3, Reactor Core Parameters (NIST, 2009). In that Technical Specification 15\% $\Delta \mathrm{k} / \mathrm{k}$ is set as the maximum excess reactivity for any NBSR core configuration. Calculations have shown that a full set (30 fuel elements) of fresh LEU fuel elements in the core will have an excess reactivity of $15.6 \% \Delta \mathrm{k} / \mathrm{k}$. This is considerably larger than the $6.7 \%(6.3 \%)$ for the HEU (LEU) equilibrium core and above the Technical Specification limit. Additionally, a core with $100 \%$ fresh fuel elements could not be maintained in the shutdown state with the most reactive shim arm retracted, which would be another violation of the NBSR Technical Specification 3.3.

Another scenario rejected is to have the core fueled completely with LEU fuel but with differing amounts of ${ }^{235} \mathrm{U}$ in the fuel elements to simulate the burnup expected in an equilibrium core. This requires either a change in enrichment and/or loading in many fuel elements; either way undesirable because of the added complication in fuel fabrication. 
The most straightforward way to make the transition is expected to be the use of the current fuel management scheme so that only four LEU elements are introduced in each cycle. Although this means that it will take eight cycles to fully remove all the HEU fuel, this is not seen as problematic. The use of eight transition cores and the resulting neutronic properties is the subject of this report.

Chapter 2 discusses the properties of the transition cores after an explanation of the fuel management scheme and the calculational methodology used in the analysis. The properties of interest are the cycle length, shim arm parameters, kinetics parameters, power factors, reactivity coefficients, figures-of-merit for neutron beam performance, and actinide inventories at discharge. The chapter also deals with the issues of what happens after the transition cores are completed and the potential for a preliminary step involving the partial loading of LEU fuel before the actual transition called the lead acceptance element approach. 


\section{TRANSITION CORE PROPERTIES}

\subsection{Fuel Management Scheme}

The replacement plan for the NBSR to transition from HEU fuel to LEU fuel maintains the fuel management scheme that has been used for the HEU fuel. Figure 2-1 shows the fuel element position designations for the 30 fuel elements, which lie in a triangular pitch. There are seven numbered rows (1-7) and 13 lettered columns (A-M). The positions denoted by $<>$ are the locations of the 3.5-inch in-core irradiation thimbles and the position denoted by $<\mathrm{RR}>$ is the regulating rod. The location of the major cold source is shown on the figure.

The fuel elements (FEs) are designated with two numbers and one letter, either $\mathrm{E}$ or $\mathrm{W}$ for East or West side of the core. The first number is either a 7 or 8 indicating the fuel elements that will be in the core for 7 or 8 cycles. The second number, 1 through 8 , indicates the present fuel cycle for the given fuel element. Hence the 7-1 and 8-1 fuel elements are fresh, unirradiated fuel elements. The 7-7 and 8-8 are FEs in their final cycle. At the end of each 38.5-day cycle, the four FEs labeled 7-7E, 7-7W, 8-8E and 8-8W are removed from the core. The 7-6E FE is moved into the 7-7E position. Likewise the 8-7W FE is moved into the $8-8 \mathrm{~W}$ position, noting that the FEs always stay in either the east or west half of the core. All the fuel elements are relocated in this manner, until the four 7-1 and 8-1 positions are vacant. Fresh fuel elements are then loaded into those positions.

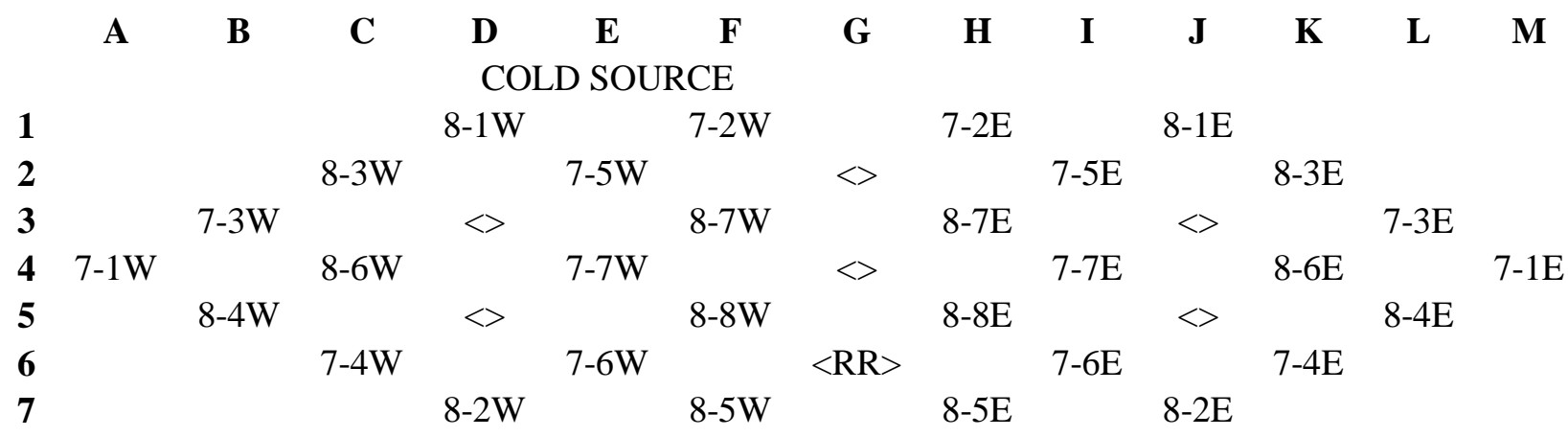

Figure 2-1 Fuel Management Scheme

This same scheme would be used for the transition cores. Four fresh LEU fuel elements are loaded in the first transition core. At the end of the first and the next five cycles, four spent HEU fuel elements are removed from the core and four fresh LEU fuel elements are loaded. Transition core 7 is the final mixed core containing only two HEU fuel elements (in the 8-8 positions). At the end of that cycle both HEU and LEU fuel is removed. In transition core 8 the transition from HEU to LEU will be completed. However several additional cycles of operation will be needed before a true equilibrium condition is established (Section 2.10). In the present study transition core 8 is considered close enough to the equilibrium core to end the calculation. The number of each of the two types of fuel elements in each transition core (TC) is shown in Table 2-1. 
Table 2-1 Number of Different FEs in Transition Cores

\begin{tabular}{|c|c|c|}
\hline & No. of LEU FEs & No. of HEU FEs \\
\hline TC1 & 4 & 26 \\
\hline TC2 & 8 & 22 \\
\hline TC3 & 12 & 18 \\
\hline TC4 & 16 & 14 \\
\hline TC5 & 20 & 10 \\
\hline TC6 & 24 & 6 \\
\hline TC7 & 28 & 2 \\
\hline TC8 & 30 & 0 \\
\hline
\end{tabular}

\subsection{Reactor Model and Inventory Calculations}

The inventory or material composition for each half fuel element (a total of 60 materials) was calculated using MCNPX-2.60 (Pelowitz, 2011) with the BURN option, as described in (Hanson, 2011). The procedure is a bit more complicated than for an equilibrium core since analyzing the inventories of the HEU fuel elements is different than analyzing the inventories in the LEU fuel elements, which have a different initial composition. The flow chart of the analysis for the eight transition cores is shown in Figure 2-2.

The initial inventories for the first transition core (TC1) are the HEU equilibrium inventories for 26 HEU fuel elements that have gone through 1-7 cycles plus the composition of a fresh LEU fuel element (applied to four fuel elements). For each transition core, inventories are kept for the following statepoints during the fuel cycle:

- Startup (SU); with fresh fuel and the absence of short-lived fission products

- Beginning-of-cycle (BOC); after 1.5 days when important fission products are present

- Mid-cycle (MID); midway in the fuel cycle

- End-of-cycle (EOC); at the end of the cycle when all shim arms are withdrawn

Once the inventories were determined for each transition core, the kinetics parameters, power distributions, neutron beam performance, etc. were studied for each step in the transition. However, for each TC not all parameters were given for each of the four statepoints for which the inventories are available. For example, excess reactivity and shutdown margin are only of interest at the most reactive statepoint, which is SU, and many other parameters are only of interest at SU and EOC. SU tends to be most limiting for some accidents because power peaking is highest and EOC tends to be the most limiting for some because shim arm worth vs time is minimized after reactor trip at EOC when shim arms are withdrawn to their fully withdrawn (horizontal) position. 


\subsection{Cycle Length}

The NBSR is presently operated with a nominal cycle length of 38.5 days. The LEU fuel is designed to maintain that cycle length after conversion. At EOC the shim arms are totally withdrawn and the multiplication factor, $\mathrm{k}_{\mathrm{eff}}$, for the reactor should be unity. The HEU model has been validated by comparing results with operational data. However, due to uncertainties in the model the calculated multiplication factor at EOC is $\mathrm{k}_{\mathrm{eff}} \approx 1.006$. The LEU equilibrium core was designed to have this same value of the multiplication factor as the present model for the HEU fuel. This assumes that the bias comes from the model (e,g., cross sections, geometry assumptions, statistics) and not from the type of fuel used.

This value of $k_{\text {eff }}$ at EOC was also used as the criterion for each transition core to operate for 38.5 days. When four fresh LEU fuel elements are placed in the NBSR at TC1 the excess reactivity at SU decreases by $\sim 0.4 \%$ (see Section 2.4 ) and for a cycle length of 38.5 days the value of $\mathrm{k}_{\mathrm{eff}}$ at EOC is 1.002, hence the reactor would be expected to become subcritical prior to the desired 38.5-day cycle length. This is illustrated in Figure 2-3 which shows four curves. The horizontal line labeled HEU is the value of $\mathrm{k}_{\mathrm{eff}}$ at EOC for the HEU core. The line labeled 38.5d is from calculated values of $\mathrm{k}_{\mathrm{eff}}$ at EOC if the NBSR could be run for 38.5 days during the transition. From that curve, the value of $\mathrm{k}_{\text {eff }}$ for TC1 at EOC would fall below 1.006 prior to the end of 38.5 days and subsequent transition cores would likewise not operate for 38.5 days. Therefore, it was decided to investigate shortening the first cycle enough to allow each subsequent transition cycle to operate for a full 38.5. The other two curves in Figure 2-3 are the values of $k_{\text {eff }}$ at EOC if TC1 was shortened to either 22 days or 24 days and each subsequent transition core operated for 38.5 days. If the first cycle were to be shortened to 24 days, then TC6 would not be able to operate for a full 38.5 days. These results indicate that the first cycle would need to be shortened to 22 days in order for each subsequent cycle to be a full 38.5 days.

If TC1 is shortened to 22 days, the value of $\mathrm{k}_{\mathrm{eff}}$ at the end of each cycle is larger than the equilibrium value and decreases with cycle until cycle 6 has been completed. The variation in $\mathrm{k}_{\mathrm{eff}}$ at EOC implies that the shim arm position for each subsequent startup will likewise vary. This is confirmed in Figure 2-4, a plot of the angle of the shim arms (relative to horizontal) needed for criticality at SU for all transition cores and the equilibrium HEU and LEU cores. 


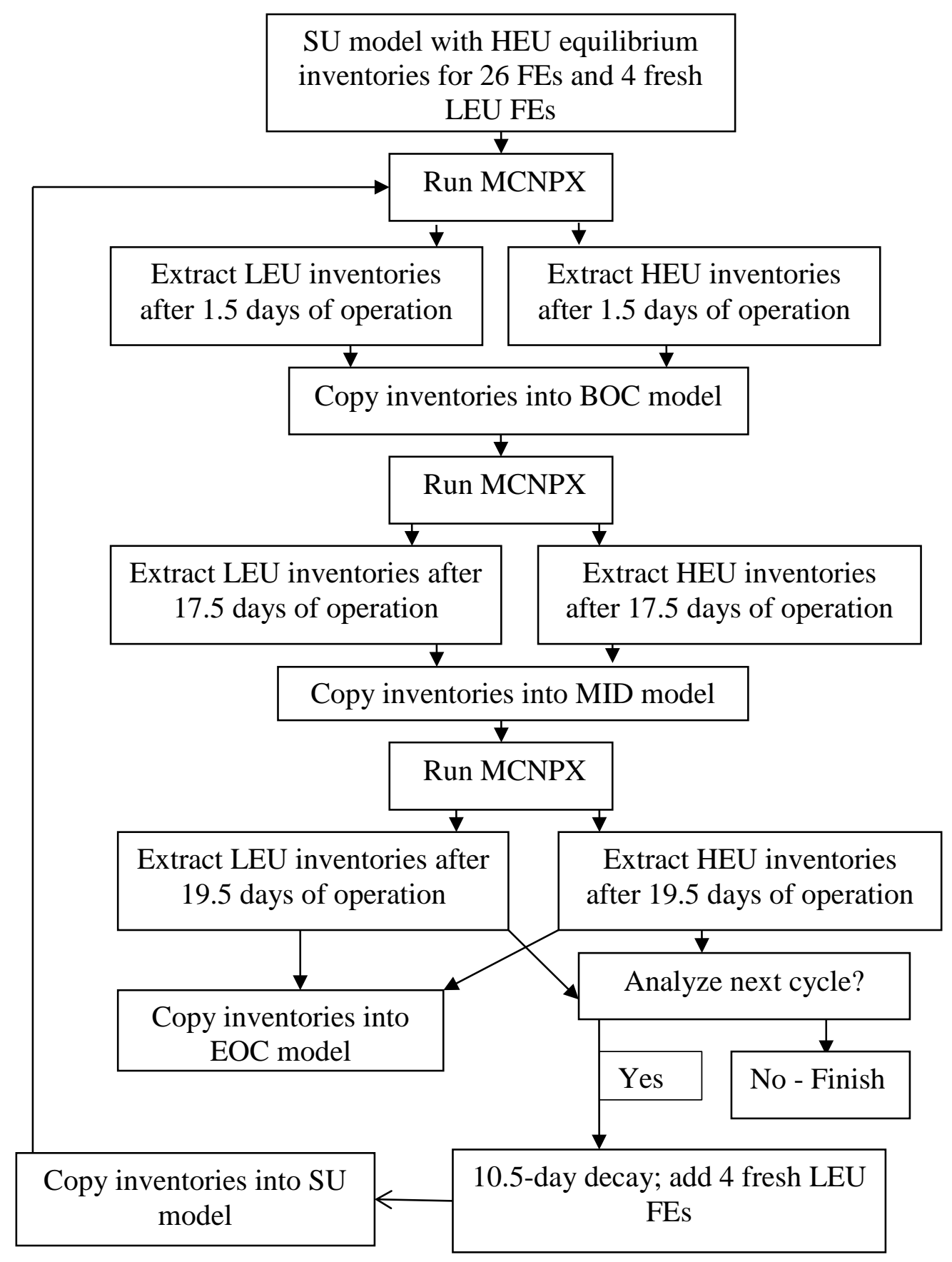

Figure 2-2 Flow Chart for Generating Inventories in a Mixed Core with MCNPX 


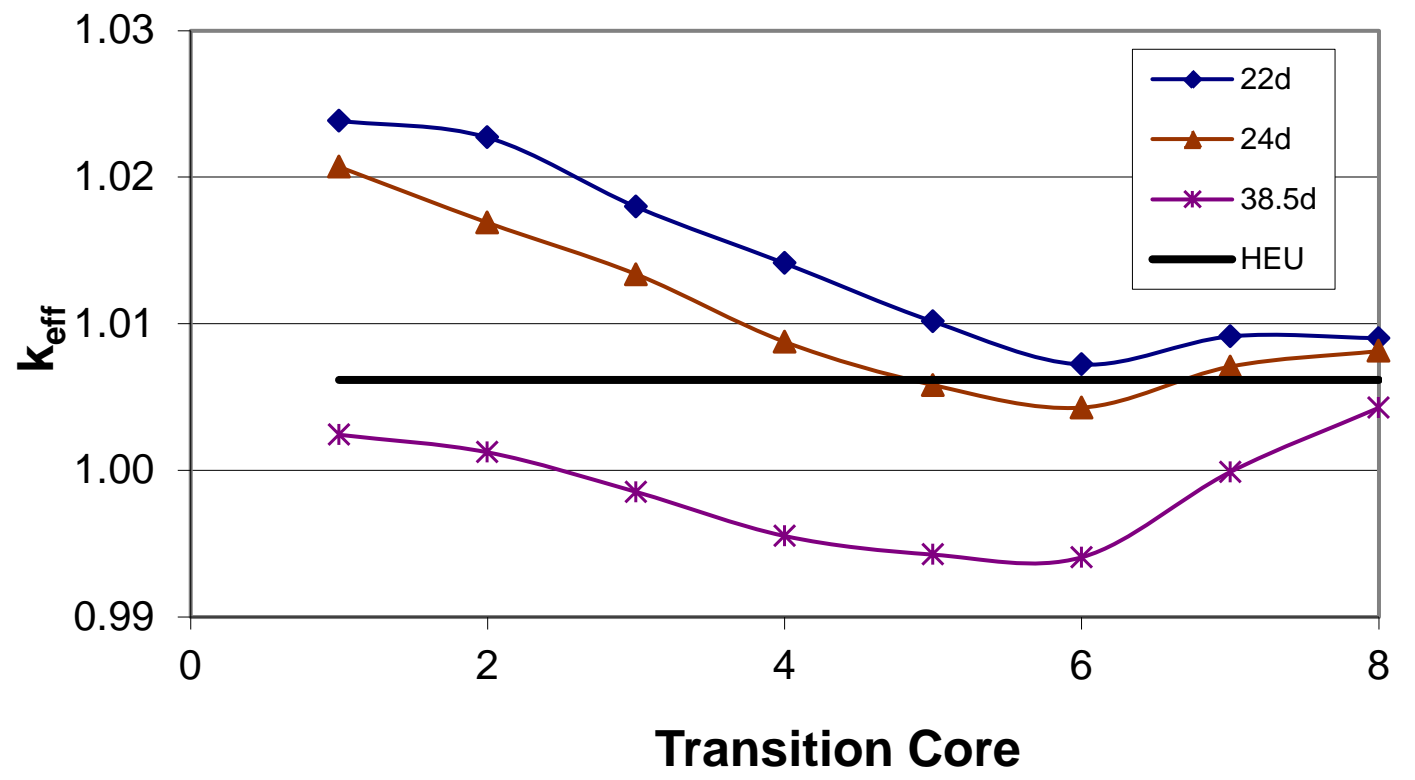

Figure 2-3 $k_{\text {eff }}$ at EOC for Different TC1 Cycle Lengths and the HEU Core

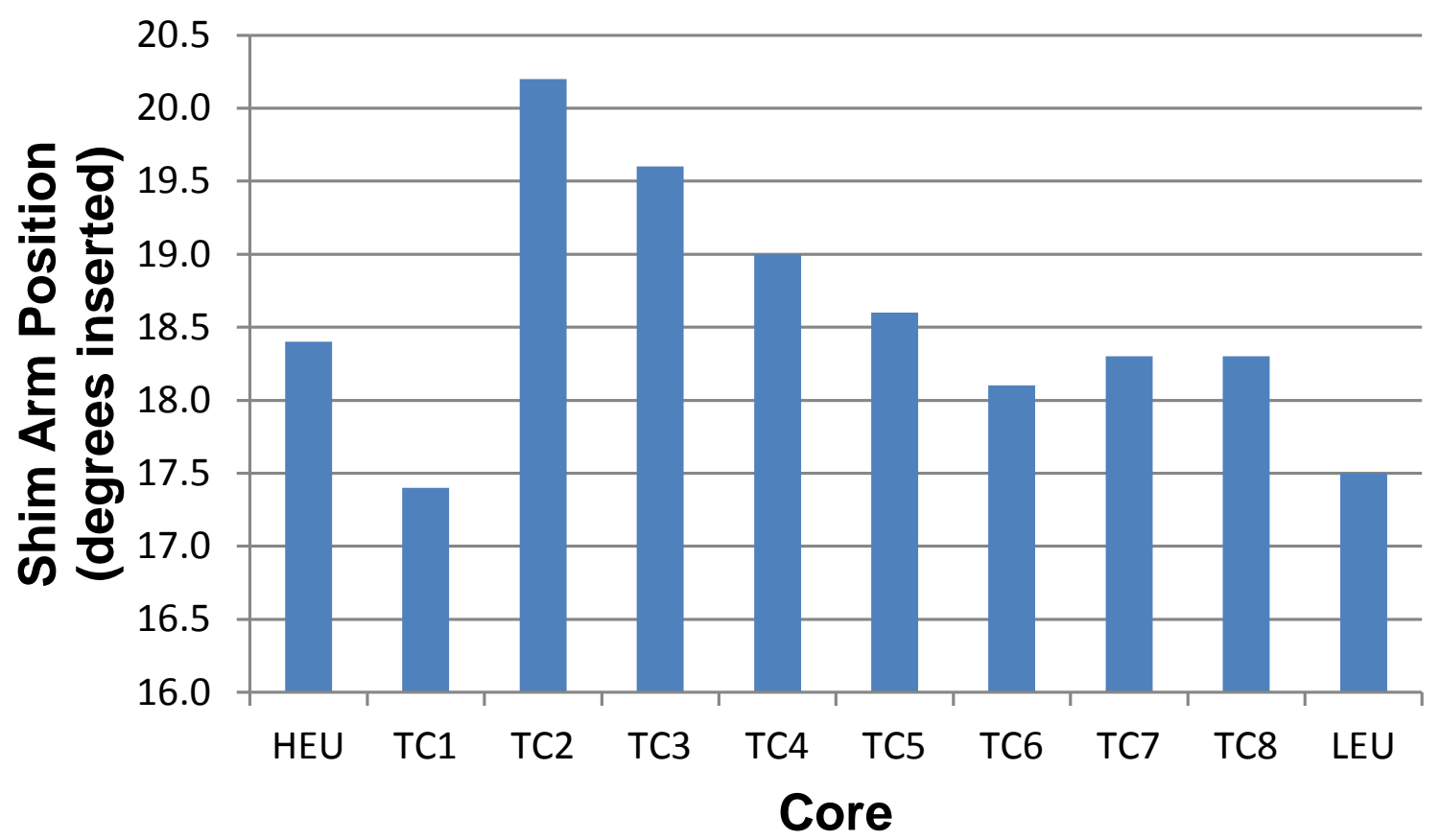

Figure 2-4 Shim Arm Angle at SU for Criticality for each Transition Core 


\subsection{Shim Arm Reactivity}

NBSR Technical Specification 3.1.2, Reactivity Limitations (NIST, 2009) states that the core cannot be loaded such that the excess reactivity will exceed $15 \% \Delta \mathrm{k} / \mathrm{k}$ and that the NBSR shall not be operated if it cannot be kept shutdown by at least $0.757 \% \Delta \mathrm{k} / \mathrm{k}$ with the most reactive shim arm fully withdrawn.

Table 2-2 shows the SU core values for the shutdown reactivity (SR, all shims in), the shutdown margin (SDM, three shim arms inserted and one withdrawn) along with the excess reactivity (ER, all shim arms removed) for the HEU equilibrium core, each transition core and the LEU equilibrium core. These results assume the length of TC1 is 22 days and each subsequent transition core to operate for 38.5 days. This table demonstrates that the excess reactivity drops from $6.7 \%$ to $6.4 \%$ when the first four LEU fuel elements are loaded in the core. Even though the mid-transition cores have excess reactivity that falls below the values for either full HEU or LEU cores, the values of $\mathrm{k}_{\mathrm{eff}}$ at EOC (Figure 2-3) demonstrate that the reactor should operate for the full 38.5 days. This table demonstrates that the NBSR Technical Specification 3.1.2 is met for each transition core.

Table 2-2 Shutdown Reactivity, Shutdown Margin, and Excess Reactivity

\begin{tabular}{|c|c|c|c|c|c|c|c|c|c|c|}
\hline & \multicolumn{10}{|c|}{ Reactivity, \% $\mathbf{\Delta k} / \mathbf{k}$} \\
\hline & HEU & TC1 & TC2 & TC3 & TC4 & TC5 & TC6 & TC7 & TC8 & LEU \\
\hline SR (all shim arms in) & -18.2 & -18.6 & -16.7 & -17.3 & -17.8 & -18.1 & -18.4 & -18.0 & -18.1 & -18.3 \\
\hline SDM - Shim 1 out & -12.1 & -12.6 & -10.7 & -11.0 & -11.6 & -12.0 & -12.2 & -12.1 & -12.0 & -12.2 \\
\hline SDM - Shim 2 out & -11.0 & -11.4 & -9.5 & -9.9 & -10.4 & -10.8 & -11.1 & -11.0 & -10.9 & -11.2 \\
\hline SDM - Shim 3 out & -10.0 & -10.5 & -9.0 & -9.8 & -10.2 & -10.6 & -10.9 & -10.5 & -10.6 & -10.8 \\
\hline SDM - Shim 4 out & -11.5 & -12.0 & -10.3 & -10.8 & -11.3 & -11.7 & -12.0 & -11.7 & -11.8 & -11.9 \\
\hline ER (all shim arms out) & 6.7 & 6.4 & 7.8 & 7.4 & 6.9 & 6.5 & 6.2 & 6.1 & 5.9 & 6.3 \\
\hline
\end{tabular}

The shim arm reactivity vs. position (differential worth) curves have the same shape for the HEU and LEU cores, but different total (integral) worths (Hanson, 2011). Table 2-3 provides the calculated shim arm worth at SU and EOC for the HEU and LEU equilibrium cores and each transition core. Changes through the transition are not significant.

Table 2-3 Total Shim Arm Worth

\begin{tabular}{|c|c|c|c|c|c|c|c|c|c|c|}
\hline & \multicolumn{10}{|c|}{ Reactivity, \% $\mathbf{\Delta k} / \mathbf{k}$} \\
\hline & HEU & TC1 & TC2 & TC3 & TC4 & TC5 & TC6 & TC7 & TC8 & LEU \\
\hline SU & 24.9 & 25.1 & 24.7 & 24.8 & 24.7 & 24.7 & 24.5 & 24.2 & 24.1 & 24.6 \\
\hline EOC & 27.2 & 26.5 & 26.7 & 26.6 & 26.7 & 26.5 & 26.3 & 25.9 & 25.7 & 26.0 \\
\hline
\end{tabular}




\subsection{Prompt Neutron Lifetime and Delayed Neutron Fraction}

The calculated prompt neutron lifetime and the delayed neutron fraction at SU are shown in Table 2-4 for the HEU and LEU equilibrium cores and several of the transition cores. They are calculated as explained in (Hanson, 2012a). The delayed neutron fractions herein do not include the effect of photoneutrons. This table indicates that the values of the neutron lifetime and delayed neutron fraction for the transition cores lie between the values for the HEU and the LEU cores. The neutron lifetime recommended for the LEU core at SU (600 $\mu$ s) (Hanson, 2012a) is conservative not only for the equilibrium LEU core but also for the transition cores. Using values for both neutron lifetime and delayed neutron fraction for the LEU fuel will be conservative for any transition core.

Table 2-4 Prompt Neutron Lifetime and Delayed Neutron Fraction

\begin{tabular}{|c|c|c|c|c|}
\hline Fuel & $\begin{array}{c}\text { Lifetime } \\
(\boldsymbol{\mu s})\end{array}$ & \pm & $\boldsymbol{\beta}$ & \pm \\
\hline HEU & 698 & 1 & 0.00665 & 0.00005 \\
\hline TC1 & 699 & 1 & 0.00665 & 0.00005 \\
\hline TC3 & 672 & 1 & 0.00665 & 0.00005 \\
\hline TC4 & 671 & 1 & 0.00663 & 0.00005 \\
\hline TC7 & 650 & 1 & 0.00651 & 0.00005 \\
\hline LEU & 651 & 1 & 0.00650 & 0.00005 \\
\hline
\end{tabular}

\subsection{Power Distributions}

The power distribution throughout the core is calculated on a $\sim 2 \times 2 \mathrm{~cm}$ mesh in every fuel plate; a total of 42840 mesh boxes for the 34 plates in each of the 30 fuel elements in the core. The use of a mesh of this size allows for a conservative estimate of the peak heat flux (as justified by heat transfer calculations (Cheng, 2010)). This means that each plate in a half-element has 14 mesh intervals axially and three laterally, with the latter then being vertical stripes. The resulting power distributions are best understood by considering three key parameters for a given time in the cycle:

- hottest point (mesh) in the core

- hottest stripe; (14 mesh points)

- half-element power (total of 17 plates)

The power distributions are based on a burnup distribution that is uniform across each of the 60 half-elements in the core. It is known that this assumption leads to conservative power distributions (Brown, 2013a). However, this approach is satisfactory to use as the basis for the safety analysis.

The results presented below have been normalized so that unity is the average power across the core, or $20 \mathrm{MW} / 42840=467 \mathrm{~W}$ per mesh square $=117 \mathrm{~W} / \mathrm{cm}^{2}$ with the assumption that there is

November 13, 2013 
a one-to-one correspondence between the fission density (which is actually calculated) and the power density. There are a total of 3060 vertical stripes so those results are normalized to the average stripe power of $20 \mathrm{MW} / 3060=6.54 \mathrm{~kW}$ per stripe.

The results for the hottest points, stripes and half fuel elements are summarized in Table 2-5 for SU and Table 2-6 for EOC. The first column is the step in the transition with HEU and LEU being the values for the equilibrium cores. The second column is the relative value (core average being unity) for the hottest point in the core and the third column identifies the location in terms of fuel element identification and whether the spot is the upper (U) or lower (L) half-element. The fourth column identifies the fuel element type (either HEU or LEU) at that location for that core. Columns 2-4 are repeated for the hottest stripe and the hottest half fuel element.

Table 2-5 Hottest Spots, Stripes and Half Fuel Elements at SU

\begin{tabular}{|c|c|c|c|c|c|c|c|c|c|}
\hline & \multicolumn{3}{|c|}{ Hottest Spot } & \multicolumn{3}{|c|}{ Hottest Stripe } & \multicolumn{3}{|c|}{ Hottest Half FE } \\
\hline & Rel. Value & Cycle Pos. & Fuel & Rel. Value & Cycle Pos. & Fuel & Rel. Value & Cycle Pos. & Fuel \\
\hline HEU & 2.48 & $7-2 \mathrm{E} / \mathrm{L}$ & HEU & 1.81 & $8-3 \mathrm{E} / \mathrm{L}$ & HEU & 1.28 & $7-5 \mathrm{E} / \mathrm{L}$ & HEU \\
\hline TC1 & 2.42 & $7-2 \mathrm{E} / \mathrm{L}$ & HEU & 1.78 & 7-1W/L & LEU & 1.26 & 8-7W/L & HEU \\
\hline TC2 & 2.53 & $7-2 \mathrm{E} / \mathrm{L}$ & LEU & 1.78 & 8-3E/L & HEU & 1.34 & 8-7E/L & HEU \\
\hline TC3 & 2.55 & $7-3 \mathrm{E} / \mathrm{L}$ & LEU & 1.90 & 7-3W/L & LEU & 1.32 & 8-7W/L & HEU \\
\hline TC4 & 2.59 & $8-4 \mathrm{~W} / \mathrm{L}$ & LEU & 1.92 & $8-4 \mathrm{~W} / \mathrm{L}$ & LEU & 1.32 & $8-7 \mathrm{~W} / \mathrm{L}$ & HEU \\
\hline TC5 & 2.70 & 7-5W/L & LEU & 2.02 & 7-5W/L & LEU & 1.37 & $7-5 W / L$ & LEU \\
\hline TC6 & 2.60 & 7-5W/L & LEU & 1.96 & $7-5 W / L$ & LEU & 1.33 & $8-6 W / L$ & LEU \\
\hline TC7 & 2.63 & $7-5 W / L$ & LEU & 1.92 & $7-7 \mathrm{~W} / \mathrm{L}$ & HEU & 1.44 & $7-7 \mathrm{~W} / \mathrm{L}$ & LEU \\
\hline TC8 & 2.53 & $7-5 \mathrm{~W} / \mathrm{L}$ & LEU & 1.91 & $7-5 \mathrm{~W} / \mathrm{L}$ & LEU & 1.40 & 8-7W/L & $\overline{\mathrm{LEU}}$ \\
\hline LEU & 2.43 & 8-3E/L & LEU & 1.78 & 8-3E/L & LEU & 1.35 & 8-7W/L & LEU \\
\hline
\end{tabular}

Table 2-6 Hottest Spots, Stripes and Half Fuel Elements at EOC

\begin{tabular}{|c|c|c|c|c|c|c|c|c|c|}
\hline & \multicolumn{3}{|c|}{ Hottest Spot } & \multicolumn{3}{|c|}{ Hottest Stripe } & \multicolumn{3}{|c|}{ Hottest Half FE } \\
\hline & Rel. Value & $\begin{array}{l}\text { Cycle } \\
\text { Pos. }\end{array}$ & Fuel & Rel. Value & $\begin{array}{c}\text { Cycle } \\
\text { Pos. }\end{array}$ & Fuel & Rel. Value & Cycle Pos. & Fuel \\
\hline HEU & 2.19 & 7-1W/U & HEU & 1.66 & $7-2 \mathrm{E} / \mathrm{U}$ & HEU & 1.18 & $7-2 \mathrm{E} / \mathrm{U}$ & HEU \\
\hline TC1 & 2.26 & 7-1E/U & LEU & 1.64 & $7-2 \mathrm{E} / \mathrm{U}$ & HEU & 1.14 & $7-2 \mathrm{E} / \mathrm{U}$ & HEU \\
\hline TC2 & 2.27 & 7-1E/U & LEU & 1.73 & $7-2 \mathrm{E} / \mathrm{U}$ & LEU & 1.15 & $7-2 \mathrm{E} / \mathrm{U}$ & LEU \\
\hline TC3 & 2.43 & 7-3W/L & LEU & 1.73 & $7-3 W / L$ & LEU & 1.14 & $7-3 \mathrm{E} / \mathrm{U}$ & LEU \\
\hline TC4 & 2.42 & 7-3W/L & LEU & 1.67 & 7-3W/L & LEU & 1.12 & $7-5 \mathrm{E} / \mathrm{U}$ & HEU \\
\hline TC5 & 2.38 & 7-3W/L & LEU & 1.66 & 7-3W/L & LEU & 1.16 & $7-5 \mathrm{E} / \mathrm{U}$ & $\mathrm{LEU}$ \\
\hline TC6 & 2.29 & 7-3W/L & LEU & 1.64 & 7-3W/L & LEU & 1.12 & $7-5 \mathrm{~W} / \mathrm{U}$ & $\mathrm{LEU}$ \\
\hline TC7 & 2.28 & 7-3W/L & LEU & 1.63 & 7-3W/L & LEU & 1.16 & 7-7W/L & LEU \\
\hline TC8 & 2.25 & 8-3W/L & LEU & 1.61 & 7-3W/L & LEU & 1.12 & 8-7W/L & LEU \\
\hline LEU & 2.21 & 7-3E/U & LEU & 1.65 & $7-2 \mathrm{E} / \mathrm{U}$ & LEU & 1.15 & 8-7E/U & LEU \\
\hline
\end{tabular}


The results show that the hottest spot at $\mathrm{SU}$ is always in the lower half-element (and at the top of the element facing the midplane gap). This is due to the position of the shim arms at SU which suppresses the flux in the upper core. The hottest spot during the transition occurs in TC5 and is 9\% higher than the hottest spot in the equilibrium HEU fuel. The hottest spot occurs in the lower half of the E-2 fuel element (see Figure 2-1), which is a 7-5 fuel element with LEU fuel. The hottest stripe also occurs in TC5 and is $12 \%$ higher than for the equilibrium HEU fuel. The hottest half fuel element occurs in TC7 and is the lower half of the E-4 fuel element, which is a 7-7 fuel element. It is 13\% higher than the equilibrium HEU core.

For EOC many of the hottest spots and stripes are in a lower half-element, although for both the HEU and LEU equilibrium cores it is always in an upper half-element. The hottest spot and the hottest stripe both occur in TC3 and both in the lower half of the B-3 fuel element, which is an LEU 7-3 fuel element. However, the hottest half fuel element occurs in TC5 in the upper half of the I-2 (7-5E) fuel element. Compared to the present HEU fuel, the hottest spot at EOC is $12 \%$ higher than the hottest spot in the HEU equilibrium fuel, $4 \%$ higher for the hottest stripe, and lower for the hottest half fuel element.

The cooling system for the NBSR has two plena; the inner plenum cools the inner six fuel elements, (E4, F3, F5, H3, H5, and I4), and the outer plenum cools the other 24 fuel elements. Understanding changes in the power levels for each plenum are important in case the flow in each needs to be adjusted using valves present for that purpose. At SU the total power generated in the six central fuel elements changes from 4.00 MW for the HEU fuel to 4.36 MW for the LEU fuel, an $8.9 \%$ increase. At EOC the innermost six fuel elements generate $3.82 \mathrm{MW}$ with the HEU fuel and 4.24 MW with the LEU fuel, an $11 \%$ increase. The radial power distributions at SU for the HEU and LEU fuels are shown in Figure 2-5 and Figure 2-6, respectively, and at EOC for the HEU and LEU fuels in Figure 2-7 and Figure 2-8, respectively. These figures demonstrate that the power is more peaked towards the center of the fuel for the LEU fuel than for the HEU fuel (see also Section 2.8). These four figures demonstrate that there is a shift in the power from the outer portion of the core to the inner portion of the core when comparing the HEU and LEU fuels at equilibrium. This fact implies that there will be a shift in the power distributions during the transition from HEU to LEU fuel. This shift is demonstrated in Figure 2-9, the power generated in the six inner fuel elements during each cycle, and Figure 2-10, the power generated in the outer twenty-four fuel elements during each cycle. 
Upper Core
A
B
C D $\quad$ E $\quad$ F
G
$\begin{array}{llllll}\mathbf{H} & \mathbf{I} & \mathbf{J} & \mathbf{K} & \mathbf{L} & \mathbf{M}\end{array}$ COLD SOURCE

\begin{tabular}{|c|c|c|c|c|c|c|c|c|c|c|c|c|c|}
\hline 1 & & & & 0.98 & 列 & 1.05 & & 1.11 & & 0.99 & & & \\
\hline 2 & & & 0.95 & & 1.02 & & $<>$ & & 0.95 & & 0.82 & & \\
\hline 3 & & 0.74 & & $<>$ & & 0.91 & & 0.90 & & $<>$ & & 0.72 & \\
\hline 4 & 0.64 & & 0.71 & & 0.82 & & $<>$ & & 0.81 & & 0.70 & & 0.64 \\
\hline 5 & & 0.66 & & $<>$ & & 0.74 & & 0.74 & & $<>$ & & 0.68 & \\
\hline 6 & & & 0.72 & & 0.80 & & $<\mathrm{RR}>$ & & 0.86 & & 0.85 & & \\
\hline 7 & & & & 0.91 & & 0.91 & & 0.92 & & 0.97 & & & \\
\hline
\end{tabular}

Lower core

$\begin{array}{lllllllllllll}\text { A } & \text { B } & \text { C } & \text { D } & \text { E } & \text { F } & \text { G } & \text { H } & \text { I } & \text { J } & \text { K } & \text { L } & \text { M }\end{array}$ COLD SOURCE

\begin{tabular}{|c|c|c|c|c|c|c|c|c|c|c|c|c|c|}
\hline 1 & & & & 1.07 & & 1.17 & & 1.23 & & 1.14 & & & \\
\hline 2 & & & 1.24 & & 1.27 & & $<>$ & & 1.28 & & 1.26 & & \\
\hline 3 & & 1.25 & & $<>$ & & 1.27 & & 1.27 & & $<>$ & & 1.24 & \\
\hline 4 & 1.24 & & 1.19 & & 1.22 & & $<>$ & & 1.21 & & 1.15 & & 1.20 \\
\hline 5 & & 1.20 & & $<>$ & & 1.05 & & 1.04 & & $<>$ & & 1.15 & \\
\hline 6 & & & 1.12 & & 1.09 & & $<\mathrm{RR}>$ & & 1.08 & & 1.10 & & \\
\hline 7 & & & & 1.04 & & 0.99 & & 0.99 & & 1.03 & & & \\
\hline
\end{tabular}

Figure 2-5 Radial Power Distribution for HEU Fuel at SU

Upper Core
A
B C
D
COLD SOURCE
G
H I
$\begin{array}{llll}\text { J } & \text { K } & \text { L } & \text { M }\end{array}$

1
2
3
4
5
6
7

$1.05 \quad 0.93$

2

3

$\begin{array}{cccccccc} & & 0.91 & & 1.01 & & <> \\ 0.61 & 0.71 & & < & & 0.97 & \\ & & 0.66 & & & 0.89 & & <> \\ & & 0.72 & & 0.84 & & <\mathrm{RR}>\end{array}$

$\begin{array}{llllll}1.05 & & 0.93 & & & \\ & 0.94 & & 0.78 & & \\ 0.96 & & <> & & 0.69 & \\ & 0.89 & & 0.74 & & 0.62 \\ 0.85 & & <> & & 0.69 & \\ & 0.91 & & 0.87 & & \\ 0.94 & & 0.96 & & & \end{array}$

Lower core

$\begin{array}{lllllllllllll}\text { A } & \text { B } & \text { C } & \text { D } & \text { E } & \text { F } & \text { G } & \text { H } & \text { I } & \text { J } & \text { K } & \text { L } & \text { M }\end{array}$

\begin{tabular}{|c|c|c|c|c|c|c|c|c|c|c|c|c|c|}
\hline 1 & & & & 0.98 & & 1.09 & & 1.15 & & 1.05 & & & \\
\hline 2 & & & 1.18 & & 1.25 & & $<>$ & & 1.27 & & 1.19 & & \\
\hline 3 & & 1.20 & & $<>$ & & 1.35 & & 1.34 & & $<>$ & & 1.19 & \\
\hline 4 & 1.15 & & 1.21 & & 1.30 & & $<>$ & & 1.30 & & 1.18 & & 1.13 \\
\hline 5 & & 1.16 & & $<>$ & & 1.17 & & 1.16 & & $<>$ & & 1.12 & \\
\hline 6 & & & 1.10 & & 1.13 & & $<\mathrm{RR}>$ & & 1.12 & & 1.10 & & \\
\hline 7 & & & & 1.00 & & 1.01 & & 1.00 & & 1.01 & & & \\
\hline
\end{tabular}

Figure 2-6 Radial Power Distribution for LEU Fuel at SU 


\begin{tabular}{|c|c|c|c|c|c|c|c|c|c|c|c|c|c|}
\hline & $\begin{array}{l}\text { oer Core } \\
\text { A }\end{array}$ & B & C & D & $\mathbf{E}$ & $\mathbf{F}$ & G & $\mathbf{H}$ & I & $\mathbf{J}$ & $\mathbf{K}$ & $\mathbf{L}$ & $\mathbf{M}$ \\
\hline & & & & COL & SOU & RCE & & & & & & & \\
\hline 1 & & & & 1.00 & & 1.11 & & 1.18 & & 1.11 & & & \\
\hline 2 & & & 1.08 & & 1.11 & & $<>$ & & 1.14 & & 1.16 & & \\
\hline 3 & & 1.09 & & $<>$ & & 1.07 & & 1.07 & & $<>$ & & 1.16 & \\
\hline 4 & 1.10 & & 1.03 & & 1.04 & & $<>$ & & 1.04 & & 1.03 & & 1.1 \\
\hline 5 & & 1.08 & & $<>$ & & 0.91 & & 0.91 & & $<>$ & & 1.03 & \\
\hline 6 & & & 1.07 & & 1.02 & & $<\mathrm{RR}>$ & & 1.01 & & 1.02 & & \\
\hline 7 & & & & 1.08 & & 1.01 & & 0.99 & & 1.05 & & & \\
\hline
\end{tabular}

Lower core

$\begin{array}{lllllllllllll}\text { A } & \text { B } & \text { C } & \text { D } & \text { E } & \text { F } & \text { G } & \text { H } & \text { I } & \text { J } & \text { K } & \text { L } & \text { M }\end{array}$ COLD SOURCE

1

2

3

$4 \quad 1.05$

5

6

1.05

\begin{tabular}{|c|c|c|c|c|c|c|c|c|c|c|}
\hline & COL & SOL & RCE & & & & & & & \\
\hline & 0.85 & & 0.93 & & 0.97 & & 0.91 & & & \\
\hline 0.99 & & 0.98 & & $<>$ & & 1.00 & & 1.02 & & \\
\hline 1.02 & $<>$ & & 0.96 & & 0.97 & & $<>$ & & 1.03 & \\
\hline 0.96 & & 0.94 & & $<>$ & & 0.92 & & 0.93 & & 1.02 \\
\hline 1.01 & $<>$ & & 0.82 & & 0.81 & & $<>$ & & 0.96 & \\
\hline 0.94 & & 0.90 & & $<\mathrm{RR}>$ & & 0.88 & & 0.92 & & \\
\hline & 0.90 & & 0.87 & & 0.85 & & 0.89 & & & \\
\hline
\end{tabular}

Figure 2-7 Radial Power Distribution for HEU Fuel at EOC

Upper Core

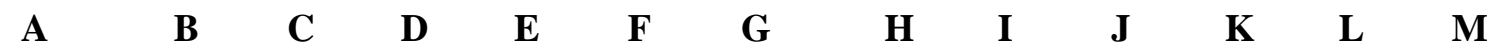
COLD SOURCE

$\begin{array}{ll}\mathbf{1} & \\ \mathbf{2} & \\ 3 & \\ \mathbf{4} & 1.02 \\ \mathbf{5} & \\ \mathbf{6} & \\ \mathbf{7} & \end{array}$

Lower core

A

B C

$\begin{array}{lll}\mathbf{D} & \mathbf{E} & \mathbf{F} \\ \text { COLD } & \text { SOURCE }\end{array}$

$\begin{array}{ll}\mathbf{1} & \\ 2 & \\ 3 & \\ 4 & 0.97 \\ 5 & \\ 6 & \\ 7 & \end{array}$

$\begin{array}{ccccccc} & & 0.93 & & 1.04 & \\ & 1.04 & & 1.11 & & <> \\ 1.04 & & <> & & 1.15 & \\ & 1.06 & & 1.14 & & <> \\ 1.05 & & <> & & 1.05 & \\ & 1.05 & & 1.06 & & <\mathrm{RR}> \\ & & 1.03 & & 1.02 & \end{array}$

1.09

1.02

$1.13 \quad 1.09$

$1.15<>$

1.10

$\begin{array}{lll}1.14 & 1.05 & 1.03\end{array}$

$1.04 \quad<>\quad 1.01$

$1.01 \quad 1.01$

1.01

\begin{tabular}{|c|c|c|c|c|c|c|c|c|c|c|}
\hline & $\mathrm{COL}$ & SOU & CE & & & & & & & \\
\hline & 0.78 & & 0.86 & & 0.91 & & 0.84 & & & \\
\hline 0.94 & & 0.98 & & $<>$ & & 1.00 & & 0.97 & & \\
\hline 0.98 & $<>$ & & 1.04 & & 1.04 & & $<>$ & & 0.98 & \\
\hline 0.98 & & 1.03 & & $<>$ & & 1.02 & & 0.96 & & 0.95 \\
\hline 0.98 & $<>$ & & 0.96 & & 0.95 & & $<>$ & & 0.94 & \\
\hline 0.94 & & 0.96 & & $<\mathrm{RR}>$ & & 0.94 & & 0.91 & & \\
\hline & 0.87 & & 0.87 & & 0.86 & & 0.85 & & & \\
\hline
\end{tabular}

Figure 2-8 Radial Power Distribution for LEU Fuel at EOC 


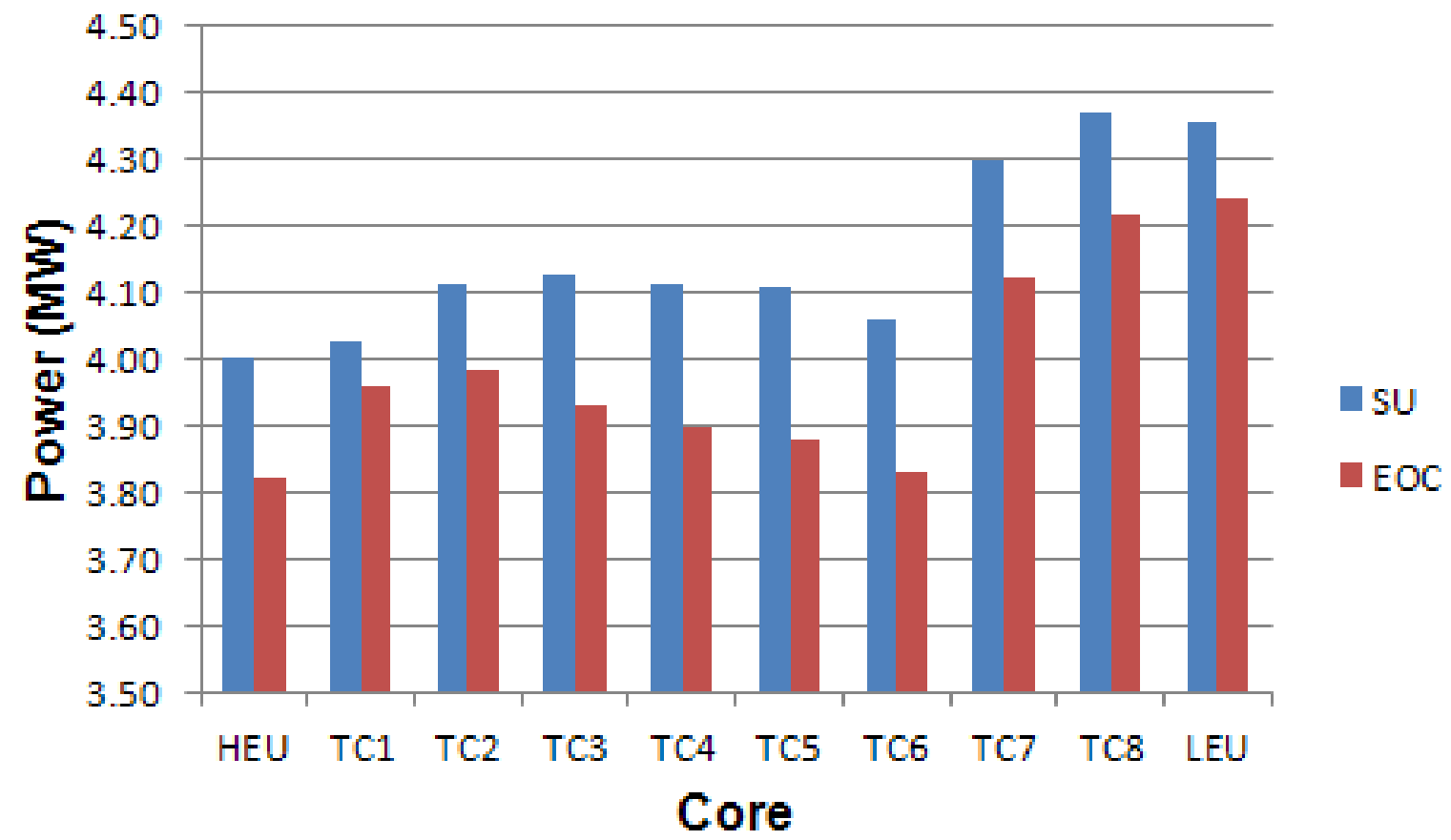

Figure 2-9 Power Generated in the Inner Six Fuel Elements at SU and EOC

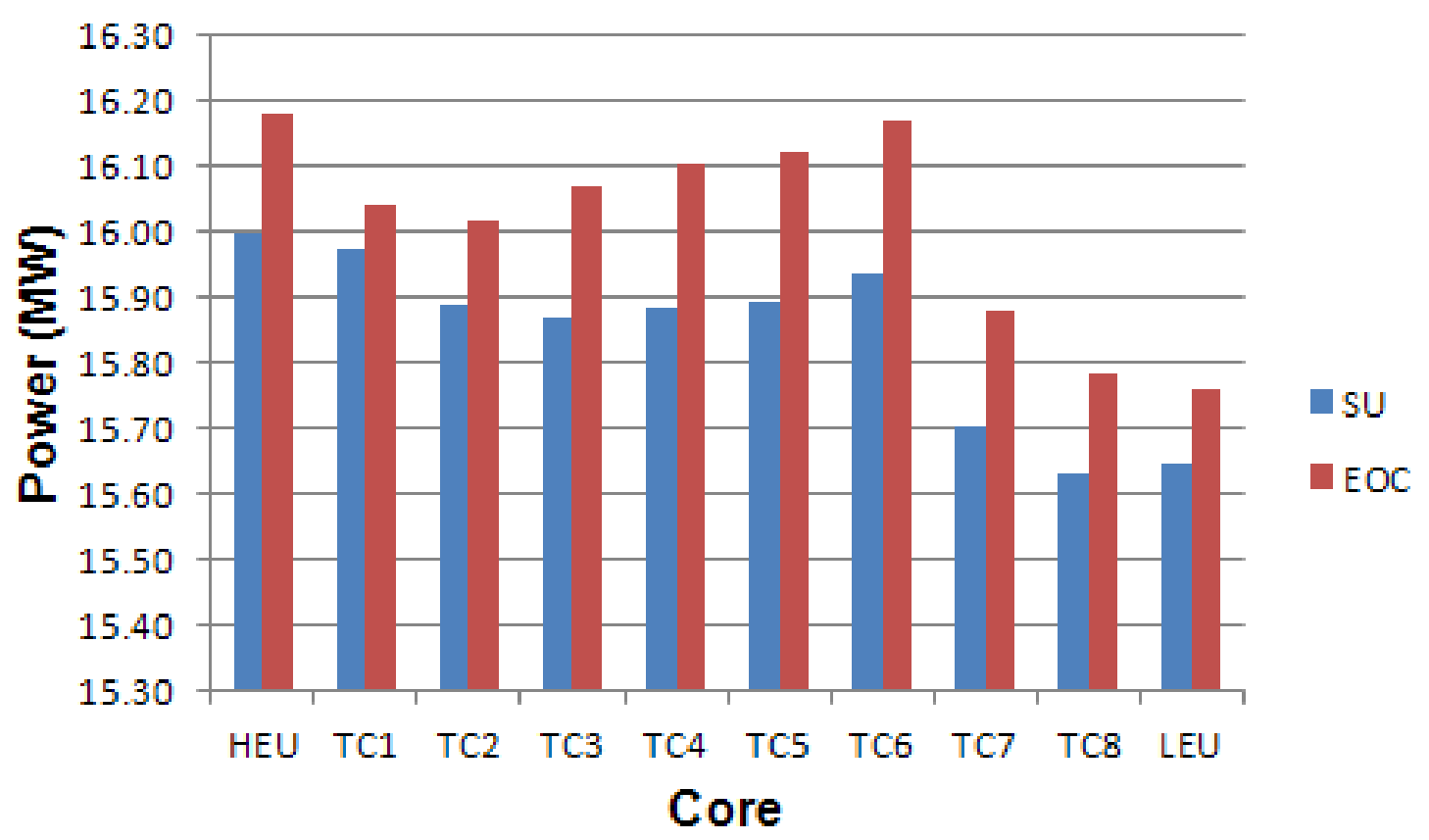

Figure 2-10 Power Generated in the Outer 24 Fuel Elements at SU And EOC 


\subsection{Reactivity Coefficients}

The moderator temperature reactivity coefficient should be negative in order to prevent positive feedback during an inadvertent power rise. Temperature coefficients have been calculated for four of the transition cores. The analysis is done in two steps. First the density of the $\mathrm{D}_{2} \mathrm{O}$ is changed (lowered) as a function of rising temperature and $\mathrm{k}_{\text {eff }}$ is calculated. This results in a contribution to the moderator temperature coefficient in $\% \Delta \mathrm{k} / \mathrm{k} /{ }^{\circ} \mathrm{C}$, after the density change is correlated to the temperature change. The second step is by changing the scattering kernel in the ENDFB-VII tables of cross sections. The two contributions are then summed together. Table 2-7 provides the calculated values and they indicate that the moderator temperature coefficients of reactivity are always negative through the transition.

Table 2-7 Moderator Temperature Coefficient (MTC)

\begin{tabular}{|l|c|c|c|c|c|c|}
\hline & \multicolumn{7}{|c|}{ MTC $\left(\% \Delta k / k /{ }^{\circ} \mathbf{C}\right)$} \\
\hline & HEU & TC1 & TC3 & TC5 & TC7 & LEU \\
\hline & \multicolumn{7}{|c|}{ SU } \\
\hline By Scattering Kernel & -0.0083 & -0.0070 & -0.0069 & -0.0060 & -0.0052 & -0.0063 \\
\hline By Density Change & -0.0215 & -0.0153 & -0.0195 & -0.0179 & -0.0179 & -0.0218 \\
\hline Total & -0.0297 & -0.0223 & -0.0265 & -0.0239 & -0.0231 & -0.0280 \\
\hline & \multicolumn{7}{|c|}{ EOC } \\
\hline By Scattering Kernel & -0.0074 & -0.0059 & -0.0053 & -0.0048 & -0.0041 & -0.0045 \\
\hline By Density Change & -0.0201 & -0.0141 & -0.0074 & -0.0133 & -0.0152 & -0.0183 \\
\hline Total & -0.0275 & -0.0201 & -0.0128 & -0.0181 & -0.0194 & -0.0228 \\
\hline
\end{tabular}

As with the moderator temperature coefficients, any bubble or void that occurs anywhere in the core should result in a drop in the power-a requirement for a negative void coefficient of reactivity. The void coefficients were calculated for voids in various locations throughout the reactor. Voids larger than any expected bubbles were used for computational purposes since the uncertainties in the calculations would be large if the changes in $\mathrm{k}_{\mathrm{eff}}$ were small. The results of those calculations are shown in Table 2-8 and indicate that any bubble or void in the NBSR will result in negative feedback. 
Table 2-8 Void Coefficient

\begin{tabular}{|c|c|c|c|c|c|c|}
\hline & \multicolumn{6}{|c|}{ Void Coefficient $(\% \Delta \mathrm{k} / \mathrm{k} / \mathrm{liter})$} \\
\hline & HEU & TC1 & TC3 & TC5 & TC7 & LEU \\
\hline & \multicolumn{6}{|c|}{ SU } \\
\hline 4 2.5-in thimbles voided & -0.045 & -0.044 & -0.043 & -0.043 & -0.046 & -0.044 \\
\hline 6 3.5-in thimbles voided & -0.036 & -0.037 & -0.036 & -0.037 & -0.039 & -0.037 \\
\hline All thimbles voided & -0.038 & -0.039 & -0.038 & -0.038 & -0.039 & -0.039 \\
\hline All FE gaps voided & -0.027 & -0.031 & -0.028 & -0.031 & -0.034 & -0.031 \\
\hline \multirow[t]{2}{*}{ All FEs voided } & -0.019 & -0.018 & -0.019 & -0.019 & -0.019 & -0.018 \\
\hline & \multicolumn{6}{|c|}{ EOC } \\
\hline 4 2.5-in thimbles voided & -0.034 & -0.034 & -0.035 & -0.032 & -0.034 & -0.035 \\
\hline 6 3.5-in thimbles voided & -0.03 & -0.031 & -0.029 & -0.030 & -0.031 & -0.032 \\
\hline All thimbles voided & -0.031 & -0.031 & -0.031 & -0.032 & -0.031 & -0.032 \\
\hline All FE gaps voided & -0.022 & -0.021 & -0.020 & -0.022 & -0.021 & -0.023 \\
\hline All FEs voided & -0.022 & -0.022 & -0.021 & -0.021 & -0.022 & -0.022 \\
\hline
\end{tabular}

\subsection{Neutron Beam Performance}

The NBSR was built for the purpose of delivering neutron beams to experimental stations. To maximize radial leakage into the neutron beam tubes, HEU was selected for the fuel, $\mathrm{D}_{2} \mathrm{O}$ was selected for the coolant and moderator and a split-core geometry was used with a 7 in $(17.8 \mathrm{~cm})$ gap between the upper and lower sections of the fuel. The conversion will result in a degradation of the neutron beam performance since the LEU fuel adds a significant amount of ${ }^{238} \mathrm{U}$ and this additional absorber reduces the flux of escaping neutrons. The neutron beam reduction after complete conversion has been calculated to be approximately 10\% (Hanson, 2011). This result is based on comparing a figure-of-merit (FOM) based on calculations of neutron flux before and after conversion at four planes in the cold neutron source and one plane in each of four beam tubes. A similar set of calculations was performed for each transition core. The FOM calculated for each transition core at both SU and EOC is shown in Figure 2-11. The FOMs for the HEU and LEU equilibrium cores are given on the figure as core numbers 0 and 9 , respectively. 


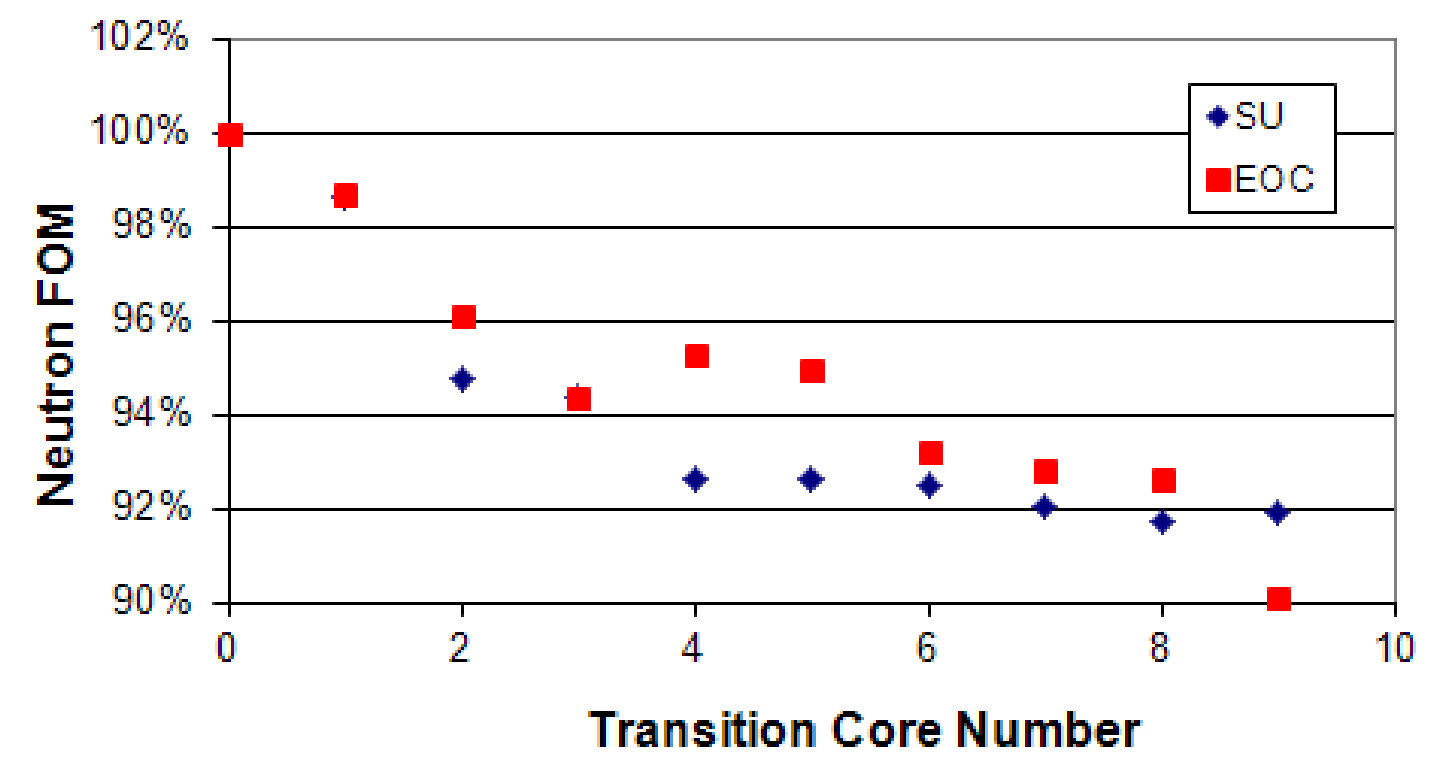

Figure 2-11 Figure-of-Merit for Neutron Beam Performance

\subsection{Discharge Actinides}

After the fuel elements are removed from the NBSR, they are allowed to cool prior to shipping for disposal. Before shipping, the fuel elements are sawed into pieces so that the fueled regions can be disposed of separately from the aluminum structure of the fuel element. The manifests required for both the transport and disposal of the spent fuel requires knowledge of the inventories in the spent fuel. The LEU fuel will have different composition when compared to the HEU fuel. Likewise the fuel elements that would be removed prematurely in order to allow the NBSR to run for its regular 38.5 day cycle will have different actinide content.

Table 2-9 and Table 2-10 show the actinide content of each half of the 7-7 and 8-8 fuel elements, respectively for the equilibrium HEU, the equilibrium LEU and each of the transition core fuel elements. These tables show that there is more unburned ${ }^{235} \mathrm{U}$ in the transition core fuel elements at discharge than there will be for the equilibrium cores; a result of the shortened first cycle. Note too that all transition cores discharge HEU fuel until the seventh cycle when LEU fuel is also discharged. 
Table 2-9 Actinide Masses for Discharged 7-Cycle Fuel Elements

\begin{tabular}{|c|c|c|c|c|c|c|c|c|c|}
\hline \multicolumn{10}{|c|}{ Actinide Mass (Grams) } \\
\hline \multicolumn{10}{|c|}{ E-4 - Upper Half } \\
\hline Actinide & HEU & TC1 & TC2 & TC3 & TC4 & TC5 & TC6 & TC7 & LEU \\
\hline${ }^{235} \mathrm{U}$ & 62.4 & 69.0 & 69.1 & 68.9 & 67.2 & 66.8 & 66.8 & 83.4 & 84.0 \\
\hline${ }^{236} \mathrm{U}$ & 17.5 & 16.5 & 16.5 & 16.5 & 16.8 & 16.8 & 16.8 & 17.0 & 16.9 \\
\hline${ }^{238} \mathrm{U}$ & 12.7 & 12.6 & 12.7 & 12.7 & 12.7 & 12.7 & 12.6 & 770.3 & 770.1 \\
\hline${ }^{237} \mathrm{~Np}$ & 0.4 & 0.3 & 0.3 & 0.3 & 0.3 & 0.3 & 0.3 & 0.3 & 0.4 \\
\hline${ }^{239} \mathrm{Pu}$ & 0.2 & 0.2 & 0.2 & 0.2 & 0.2 & 0.2 & 0.2 & 3.5 & 3.7 \\
\hline Others & 0.1 & 0.2 & 0.2 & 0.2 & 0.2 & 0.2 & 0.2 & 1.4 & 1.3 \\
\hline Tot Act Mass & 93.2 & 98.9 & 98.9 & 98.8 & 97.3 & 97.0 & 97.0 & 875.9 & 876.3 \\
\hline \multicolumn{10}{|c|}{ E-4 - Lower Half } \\
\hline & HEU & TC1 & TC2 & TC3 & TC4 & TC5 & TC6 & TC7 & LEU \\
\hline${ }^{235} \mathrm{U}$ & 60.6 & 67.1 & 67.1 & 67.4 & 66.2 & 66.6 & 66.4 & 95.7 & 81.7 \\
\hline${ }^{236} \mathrm{U}$ & 17.7 & 16.8 & 16.8 & 16.7 & 16.9 & 16.8 & 16.8 & 15.1 & 17.2 \\
\hline${ }^{238} \mathrm{U}$ & 12.6 & 12.7 & 12.7 & 12.7 & 12.6 & 12.7 & 12.7 & 771.1 & 770.0 \\
\hline${ }^{237} \mathrm{~Np}$ & 0.4 & 0.3 & 0.3 & 0.3 & 0.3 & 0.3 & 0.3 & 0.2 & 0.4 \\
\hline${ }^{239} \mathrm{Pu}$ & 0.2 & 0.2 & 0.2 & 0.2 & 0.2 & 0.2 & 0.2 & 3.4 & 3.7 \\
\hline Other Actinides & 0.2 & 0.2 & 0.2 & 0.2 & 0.2 & 0.2 & 0.1 & 1.1 & 1.4 \\
\hline Tot Act Mass & 91.6 & 97.3 & 97.2 & 97.5 & 96.4 & 96.8 & 96.6 & 886.7 & 874.2 \\
\hline \multicolumn{10}{|c|}{ I-4 - Upper Half } \\
\hline & HEU & TC1 & TC2 & TC3 & TC4 & TC5 & TC6 & TC7 & LEU \\
\hline${ }^{235} \mathrm{U}$ & 61.0 & 67.8 & 68.6 & 67.7 & 65.4 & 65.1 & 65.1 & 80.8 & 82.2 \\
\hline${ }^{236} \mathrm{U}$ & 17.7 & 16.6 & 16.5 & 16.7 & 17.0 & 17.1 & 17.1 & 17.3 & 17.1 \\
\hline${ }^{238} \mathrm{U}$ & 12.6 & 12.6 & 12.7 & 12.7 & 12.6 & 12.6 & 12.6 & 770.1 & 770.0 \\
\hline${ }^{237} \mathrm{~Np}$ & 0.4 & 0.3 & 0.3 & 0.3 & 0.3 & 0.3 & 0.3 & 0.3 & 0.4 \\
\hline${ }^{239} \mathrm{Pu}$ & 0.2 & 0.2 & 0.2 & 0.2 & 0.2 & 0.2 & 0.2 & 3.5 & 3.7 \\
\hline Other Actinides & 0.2 & 0.2 & 0.2 & 0.2 & 0.2 & 0.2 & 0.2 & 1.5 & 1.3 \\
\hline Tot Act Mass & 92.0 & 97.8 & 98.5 & 97.7 & 95.8 & 95.5 & 95.5 & 873.6 & 874.7 \\
\hline \multicolumn{10}{|c|}{ I-4 - Lower Half } \\
\hline & $\mathrm{HEU}$ & TC1 & TC2 & TC3 & TC4 & TC5 & TC6 & TC7 & LEU \\
\hline${ }^{235} \mathrm{U}$ & 60.7 & 66.5 & 67.2 & 66.8 & 64.8 & 65.8 & 64.6 & 80.5 & 82.2 \\
\hline${ }^{236} \mathrm{U}$ & 17.7 & 16.8 & 16.7 & 16.8 & 17.1 & 16.9 & 17.1 & 17.3 & 17.1 \\
\hline${ }^{238} \mathrm{U}$ & 12.6 & 12.7 & 12.7 & 12.6 & 12.6 & 12.6 & 12.7 & 770.1 & 769.9 \\
\hline${ }^{237} \mathrm{~Np}$ & 0.4 & 0.3 & 0.3 & 0.3 & 0.3 & 0.3 & 0.3 & 0.3 & 0.4 \\
\hline${ }^{239} \mathrm{Pu}$ & 0.2 & 0.2 & 0.2 & 0.2 & 0.2 & 0.2 & 0.2 & 3.5 & 3.7 \\
\hline Other Actinides & 0.2 & 0.2 & 0.2 & 0.2 & 0.2 & 0.1 & 0.1 & 1.5 & 1.3 \\
\hline Tot Act Mass & 91.8 & 96.7 & 97.3 & 96.9 & 95.2 & 96.1 & 95.1 & 873.2 & 874.6 \\
\hline
\end{tabular}


Table 2-10 Actinide Masses for Discharged 8-Cycle Fuel Elements

\begin{tabular}{|c|c|c|c|c|c|c|c|c|c|c|}
\hline \multicolumn{11}{|c|}{ Actinide Mass (Grams) } \\
\hline \multicolumn{11}{|c|}{ F-5 - Upper Half } \\
\hline & HEU & TC1 & TC2 & TC3 & TC4 & TC5 & TC6 & TC7 & TC8 & LEU \\
\hline${ }^{235} \mathrm{U}$ & 50.3 & 56.4 & 58.2 & 55.8 & 55.0 & 54.2 & 53.9 & 53.5 & 69.4 & 72.0 \\
\hline${ }^{236} \mathrm{U}$ & 19.2 & 18.3 & 18.0 & 18.4 & 18.5 & 18.6 & 18.7 & 18.7 & 19.0 & 18.6 \\
\hline${ }^{238} \mathrm{U}$ & 12.6 & 12.6 & 12.6 & 12.6 & 12.6 & 12.6 & 12.6 & 12.6 & 768.8 & 769.0 \\
\hline${ }^{237} \mathrm{~Np}$ & 0.4 & 0.4 & 0.4 & 0.4 & 0.4 & 0.4 & 0.4 & 0.4 & 0.4 & 0.4 \\
\hline${ }^{239} \mathrm{Pu}$ & .2 & 0.2 & 0.2 & 0.2 & 0.2 & 0.2 & 0.2 & 0.2 & 3.6 & 3.7 \\
\hline Other Actinides & 0.2 & 0.2 & 0.2 & 0.2 & 0.2 & 0.2 & 0.2 & 0.2 & 1.8 & 1.6 \\
\hline Tot Act Mass & 82.8 & 88.1 & 89.6 & 87.6 & 86.9 & 86.2 & 86.0 & 85.6 & 863.1 & 865.4 \\
\hline \multicolumn{11}{|c|}{ F-5 - Lower Half } \\
\hline & HEU & TC1 & TC2 & TC3 & TC4 & TC5 & TC6 & TC7 & TC8 & LEU \\
\hline${ }^{235} \mathrm{U}$ & 50.2 & 56.0 & 57.5 & 55.5 & 55.1 & 56.2 & 54.9 & 54.5 & 80.7 & 71.6 \\
\hline${ }^{236} \mathrm{U}$ & 19.2 & 18.4 & 18.2 & 18.4 & 18.5 & 18.4 & 18.5 & 18.6 & 17.3 & 18.7 \\
\hline${ }^{238} \mathrm{U}$ & 12.6 & 12.6 & 12.6 & 12.6 & 12.6 & 12.6 & 12.6 & 12.6 & 770.1 & 768.8 \\
\hline${ }^{237} \mathrm{~Np}$ & 0.5 & 0.4 & 0.4 & 0.4 & 0.4 & 0.4 & 0.4 & 0.4 & 0.3 & 0.4 \\
\hline${ }^{239} \mathrm{Pu}$ & .2 & 0.2 & 0.2 & 0.2 & 0.2 & 0.2 & 0.2 & 0.2 & 3.5 & 3.7 \\
\hline Other Actinides & .2 & 0.2 & 0.2 & 0.2 & 0.2 & 0.2 & 0.2 & 0.2 & 1.5 & 1.6 \\
\hline Tot Act $\mathrm{Mc}_{\mathrm{c}}$ & 82.7 & 87.8 & 89.0 & 87.3 & 87.0 & 87.9 & 86.8 & 86.5 & 873.4 & 864.8 \\
\hline \multicolumn{11}{|c|}{ H-5 - Upper Half } \\
\hline & $\mathrm{HEU}$ & TC1 & TC2 & TC3 & TC4 & TC5 & TC6 & TC7 & TC8 & LEU \\
\hline${ }^{235} \mathrm{U}$ & 49.6 & 55.9 & 57.0 & 55.0 & 54.1 & 52.7 & 52.1 & 51.8 & 67.8 & 71.2 \\
\hline${ }^{236} \mathrm{U}$ & 19.3 & 18.4 & 18.2 & 18.5 & 18.6 & 18.8 & 18.9 & 19.0 & 19.2 & 18.8 \\
\hline${ }^{238} \mathrm{U}$ & 12.6 & 12.6 & 12.6 & 12.6 & 12.6 & 12.6 & 12.6 & 12.6 & 768.8 & 769.0 \\
\hline${ }^{237} \mathrm{~Np}$ & 0.4 & 0.4 & 0.4 & 0.4 & 0.4 & 0.4 & 0.4 & 0.4 & 0.4 & 0.4 \\
\hline${ }^{239} \mathrm{Pu}$ & 0.2 & 0.2 & 0.2 & 0.2 & 0.2 & 0.2 & 0.2 & 0.2 & 3.6 & 3.7 \\
\hline Other Actinides & 0.2 & 0.2 & 0.2 & 0.2 & 0.2 & 0.2 & 0.2 & 0.2 & 1.8 & 1.6 \\
\hline Tot Act Mass & 82.3 & 87.7 & 88.6 & 86.9 & 86.1 & 84.9 & 84.4 & 84.2 & 861.7 & 864.6 \\
\hline \multicolumn{11}{|c|}{ F-5 - Lower Half } \\
\hline & HEU & TC1 & TC2 & TC3 & TC4 & TC5 & TC6 & TC7 & TC8 & LEU \\
\hline${ }^{235} \mathrm{U}$ & 50.1 & 56.2 & 57.0 & 55.4 & 54.4 & 54.5 & 54.3 & 53.3 & 80.2 & 70.9 \\
\hline${ }^{236} \mathrm{U}$ & 19.2 & 18.4 & 18.2 & 18.5 & 18.6 & 18.6 & 18.7 & 18.8 & 17.4 & 18.8 \\
\hline${ }^{238} \mathrm{U}$ & 12.6 & 12.6 & 12.6 & 12.6 & 12.6 & 12.6 & 12.6 & 12.6 & 769.7 & 769.1 \\
\hline${ }^{237} \mathrm{~Np}$ & 0.4 & 0.4 & 0.4 & 0.4 & 0.4 & 0.4 & 0.4 & 0.4 & 0.3 & 0.4 \\
\hline${ }^{239} \mathrm{Pu}$ & 0.2 & 0.2 & 0.2 & 0.2 & 0.2 & 0.2 & 0.2 & 0.2 & 3.6 & 3.7 \\
\hline Other Actinides & 0.2 & 0.2 & 0.2 & 0.2 & 0.2 & 0.2 & 0.2 & 0.2 & 1.5 & 1.6 \\
\hline Tot Act Mass & 82.8 & 88.0 & 88.6 & 872 & 864 & 86.5 & 86.3 & 85.5 & 872.8 & 864.5 \\
\hline
\end{tabular}




\subsection{Post-Transition Cores}

After the transition is completed and the core is fueled entirely with LEU fuel, there will still be a significant amount of time before the NBSR will reach a true equilibrium condition. This is exacerbated by the excess reactivity that was needed to be introduced with one short cycle in order to maintain the 38.5 day cycles during most of the transition. Figure 2-12 shows a plot of $\mathrm{k}_{\text {eff }}$, if the shim arms were to be completely withdrawn, as a function of cycle after the transition is completed, with " 8 " being the final step in the transition. This figure shows that the value of $\mathrm{k}_{\mathrm{eff}}$ is higher than the equilibrium value of 1.006 and that it will take several additional cycles of operation before true equilibrium is reached. However, these additional cycles are not expected to have a significant impact on the neutronic behavior of the core.

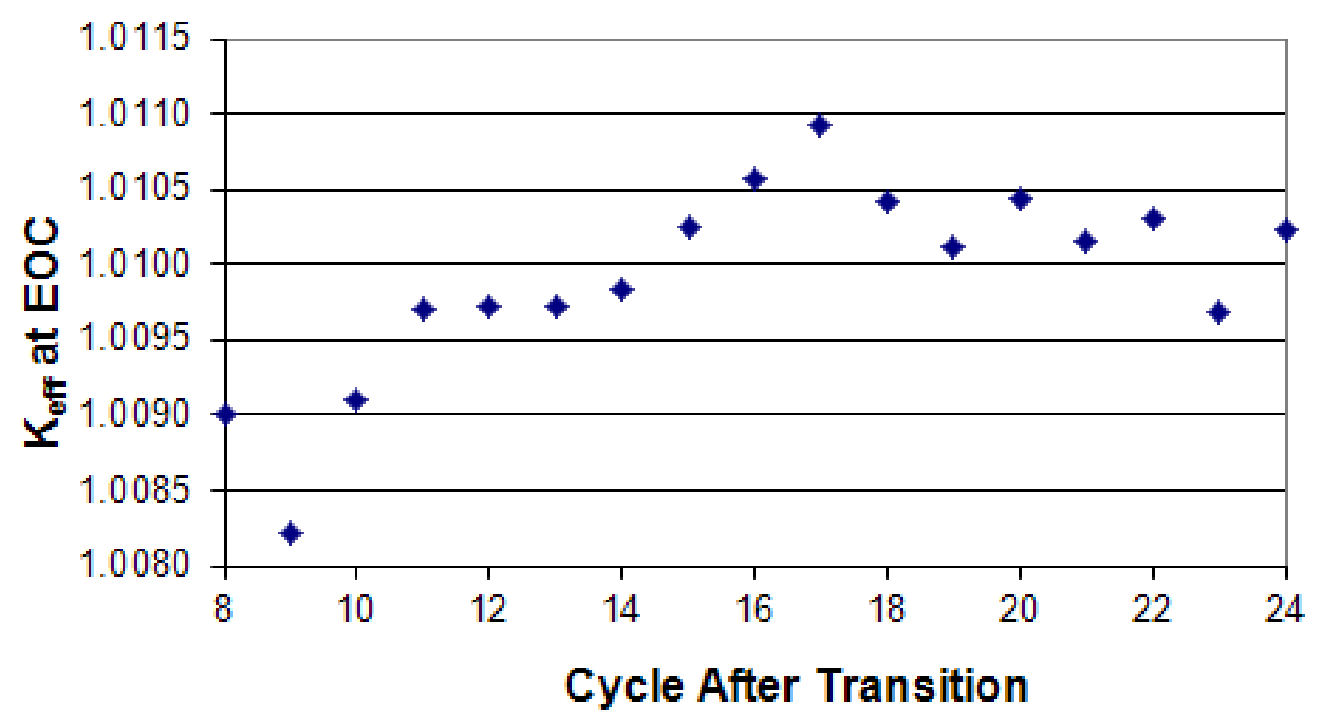

Figure 2-11 Multiplication Factor After Transition Cores

\subsection{Alternative Starting Point for the Transition}

The analysis in this report has been for a transition period of eight cycles with four fresh LEU fuel elements loaded each cycle. Another approach has also been considered. The alternative is to load two LEU and two HEU fuel elements into the core and then continue to only load four HEU elements each cycle until the LEU fuel elements are discharged after eight cycles. At this point the process would be repeated as shown in Figure 2-12. The objective of this approach would be to minimize the risk of loading in a newly designed fuel element and to maximize the use of HEU fuel that already has been fabricated. The two fresh LEU elements in the core at any time during this process are called "lead acceptance elements (LAEs)." The end of this process is determined by the inventory of HEU fuel elements that need to be used. At that end-point, the transition period would begin with four LEU fuel elements inserted in each cycle. The neutronic analysis for LAEs is found in (Hanson, 2012b). As with the transition cores discussed herein, there was insufficient excess reactivity to allow the NBSR to operate for 38.5 
days in each cycle. If the first cycle is shortened by 1.1 days, all subsequent cycles are expected to operate for 38.5 days. With only two LEU fuel elements in the core and only one shortened cycle, after 16 cycles of the LAE program, the HEU inventories were similar to the equilibrium inventories. Hence the analyses presented herein for transition cores are not expected to be significantly influenced by an LAE program prior to the transition from HEU to LEU.

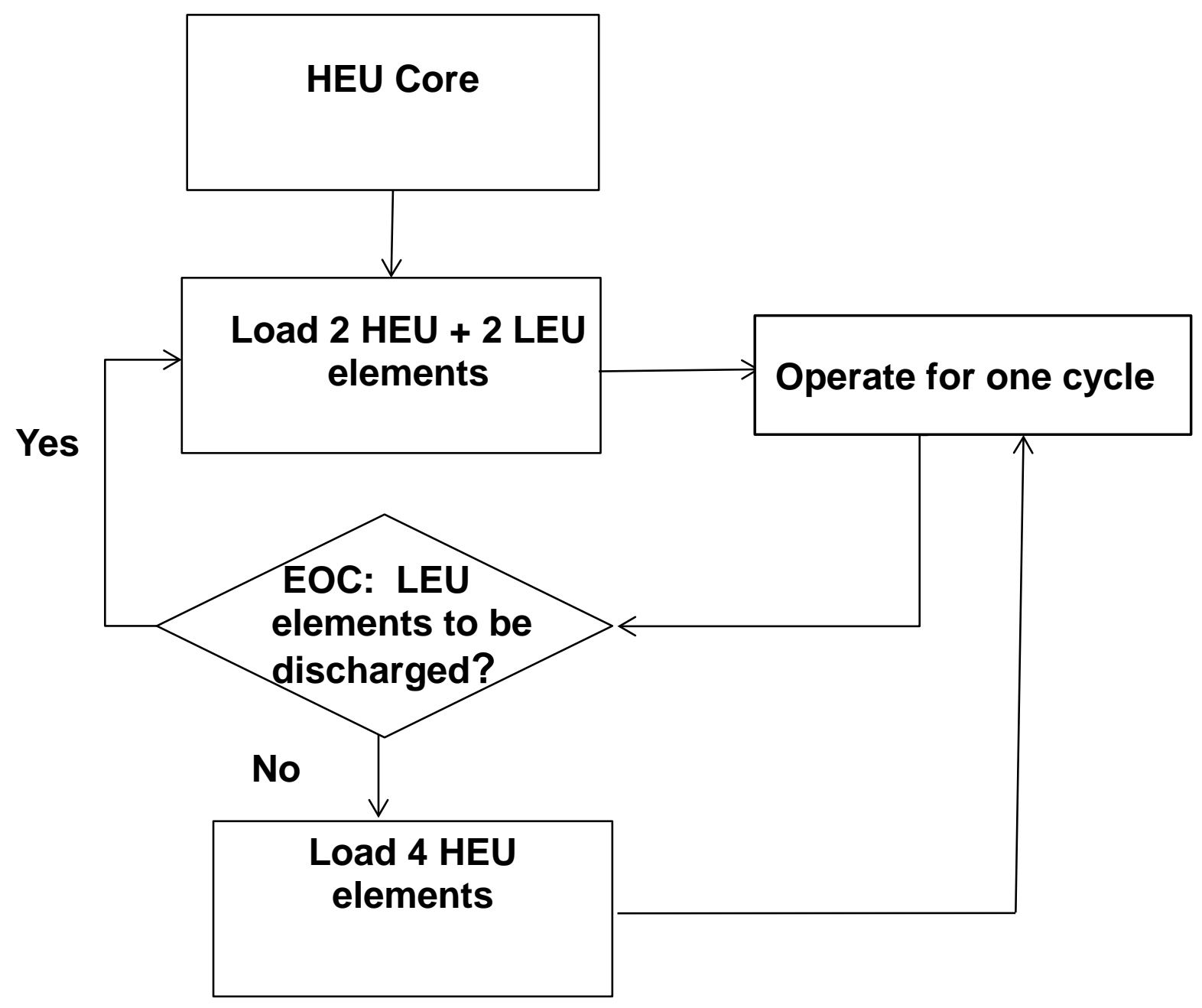

Figure 2-12 Flow Chart for Lead Acceptance Elements 


\section{SUMMARY AND CONCLUSIONS}

The conversion of the NBSR from HEU fuel to LEU fuel cannot occur with a one-time complete change of fuel from HEU to LEU because the excess reactivity would exceed the Technical Specifications for the NBSR. The option considered and analyzed for this report is to replace the fuel elements using the current fuel management scheme; adding four fresh LEU fuel elements each cycle for eight cycles at which time the entire core would consist of LEU fuel.

With this approach there is insufficient excess reactivity to keep all transition cycles at the normal 38.5-day length. Hence, it is proposed to reduce the first cycle to 22 days of operation, after which all subsequent cycles could operate for 38.5 days. The analysis of neutronic properties during these eight cycles has been carried out using MCNPX. Results for shim arm worth, kinetics parameters, and reactivity feedback coefficients, show that the transition cores will not have significant changes in these parameters. The power distributions have also been analyzed and show that the hottest point would increase $9 \%$, the hottest stripe would increase $12 \%$ and the hottest half fuel element would increase $13 \%$ during the transition. However, since the NBSR operates with a large safety margin these increases in local heating are not expected to pose a problem. A thermal-hydraulic analysis will be carried out in the future to quantify that expectation.

This study also looked at the period after the transition cores before a true equilibrium is established and noted that there will be a stable transition to the final equilibrium state. Lastly, an alternative starting point was considered wherein only two fresh LEU fuel elements were used in a "lead acceptance element" approach. If this approach were used, it is not expected to significantly alter the conclusions reached in this transition core study. 


\section{REFERENCES}

Brown, N.R., Hanson, A.L., and Diamond, D.J., "Local Burn-Up Effects in the NBSR Fuel Element,” BNL-99145-2013-IR, Brookhaven National Laboratory, Upton, NY, January 23, 2013a.

Brown, N.R., Baek, J.S., Hanson, A.L., Cuadra, A., Cheng, L-Y., and Diamond, D.J., "Irradiation Experiment Conceptual Design Parameters for NBSR Fuel Conversion, Rev.1," BNL-99897-2013-IR-R1, Brookhaven National Laboratory, Upton, NY, June 5, 2013b.

Baek, J.S., Cuadra, A., Hanson, A.L., Cheng, L-Y., Brown, N.R., and Diamond, D.J., “Accident Analysis for the NIST Research Reactor Before and After Fuel Conversion - Revision 1," BNL-98524-2012-IR-R1, Brookhaven National Laboratory, Upton, NY, June 25, 2013.

Cheng, L-Y., "Heat Conduction in an NBSR Fuel Plate-Effect on Wall Heat Flux," BNL memorandum, Brookhaven National Laboratory, Upton, NY, April 6, 2010.

Diamond, D.J., Brown, N., Hanson, A.L., Baek, J.S., and Cheng, L-Y., "NBSR Conversion Safety Analysis Report - LEU Equilibrium Core - Chapter 4,” draft report, Brookhaven National Laboratory, Upton, NY, September 4, 2012.

Hanson, A.L. and Diamond, D.J., "Calculation of Design Parameters for an Equilibrium LEU Core in the NBSR,” Technical Report, Brookhaven National Laboratory, Upton, NY, September 29, 2011.

Hanson, A.L., and Diamond, D.J., "Calculation of Kinetics Parameters for the NBSR, ” BNL97007-2012, Brookhaven National Laboratory, Upton, NY, March 2012a.

Hanson, A.L., Brown, N.R., and Diamond, D.J., “Analysis of Lead Acceptance Elements for the NBSR”, BNL Technical Report, September 25, 2012b.

Kiedrowski, B. et al., "MCNP5-1.6 Feature Enhancements and Manual Clarifications, LA-UR10-06217," Los Alamos National Laboratory, Los Alamos, NM, 2010.

NIST, “Technical Specifications for the NIST Test Reactor (NBSR),” Appendix A to License No. TR-5, National Institute of Standards and Technology (NIST), Gaithersburg, MD, 2009.

Pelowitz, D.B., "MCNPX User's Manual Version 2.7.0," Los Alamos National Laboratory, Los Alamos, NM, 2011. 